\title{
Synthesis of Vanadium Dioxide Thin Films on Conducting Oxides and Metal-Insulator Transition Characteristics
}

\section{Citation}

Cui, Yanjie, Xinwei Wang, You Zhou, Roy Gerald Gordon, and Shriram Ramanathan. 2012.

Synthesis of Vanadium Dioxide Thin Films on Conducting Oxides and Metal-Insulator Transition Characteristics. Journal of Crystal Growth 338(1): 96-102.

\section{Published Version}

doi:10.1016/j.jcrysgro.2011.10.025

\section{Permanent link}

http://nrs.harvard.edu/urn-3:HUL.InstRepos:12132061

\section{Terms of Use}

This article was downloaded from Harvard University's DASH repository, and is made available under the terms and conditions applicable to Open Access Policy Articles, as set forth at http:// nrs.harvard.edu/urn-3:HUL.InstRepos:dash.current.terms-of-use\#OAP

\section{Share Your Story}

The Harvard community has made this article openly available.

Please share how this access benefits you. Submit a story.

\section{Accessibility}




\title{
Synthesis of vanadium dioxide thin films on conducting oxides and metal-insulator transition characteristics
}

\author{
Yanjie Cui $^{\text {a }}{ }^{\star}$, Xinwei Wang ${ }^{\text {b) }}$, You Zhou ${ }^{\text {a) }}$, Roy Gordon ${ }^{\text {b) }}$ and Shriram Ramanathan ${ }^{\text {a) }}$ \\ a) Harvard School of Engineering and Applied Sciences, Harvard University, Cambridge, MA 02138 \\ b) Harvard Department of Chemistry and Chemical Biology, Harvard University, Cambridge, MA 02138 \\ *Email: cuiyanjie@hotmail.com
}

We report on growth and physical properties of vanadium dioxide $\left(\mathrm{VO}_{2}\right)$ films on model conducting oxide underlayers ( $\mathrm{Nb}$-doped $\mathrm{SrTiO}_{3}$ and $\mathrm{RuO}_{2}$ buffered $\mathrm{TiO}_{2}$ single crystals). The $\mathrm{VO}_{2}$ films, synthesized by rf sputtering, are highly textured as seen from X-ray diffraction. The $\mathrm{VO}_{2}$ film grown on $\mathrm{Nb}$ doped $\mathrm{SrTiO}_{3}$ shows over two orders of magnitude metal-insulator transition, while $\mathrm{VO}_{2}$ film on $\mathrm{RuO}_{2}$ buffered $\mathrm{TiO}_{2}$ shows a smaller resistance change but with an interesting two step transition. X-ray photoelectron spectroscopy has been performed as a function of depth on both sets of structures to provide mechanistic understanding of the transition characteristics. We then investigate voltage-driven transition in the $\mathrm{VO}_{2}$ films grown on $\mathrm{Nb}$ doped $\mathrm{SrTiO}_{3}$ substrate as a function of temperature. The present study contributes to efforts towards correlated oxide electronics utilizing phase transitions.

Keywords: A1. Characterization; A1. Substrates; A3. Physical vapor deposition processes; $\mathrm{B} 1 . \mathrm{VO}_{2} ; \mathrm{B} 2$. Metal-insulator transition materials. 


\section{INTRODUCTION}

Vanadium dioxide shows a metal-insulator transition (MIT) with several orders of magnitude conductivity change, accompanied by a phase change from high temperature tetragonal rutile structure $\left(P 4_{2} / \mathrm{mnm}\right)$ to low temperature monoclinic structure $\left(P 2_{1} / \mathrm{c}\right)$ [1]. The phase change is accomplished by a small lattice distortion along the $c$ axis of the tetragonal structure hence the formation of $\mathrm{V}-\mathrm{V}$ pairs along $a$ axis in the monoclinic structure. The transition temperature could be manipulated to either higher or lower temperature through cation substitution as investigated early in late 60 's, for example: $\mathrm{W}^{6+}, \mathrm{Nb}^{5+}, \mathrm{Ru}^{4+}$ et.al most higher valence state $\left(\geq 4+\right.$ except $\left.\mathrm{Ge}^{4+}\right)$ cation doping depress the transition temperature, while $\mathrm{M}^{3+}(\mathrm{M}=\mathrm{Cr}, \mathrm{Fe}, \mathrm{Ga}$, Al) doping elevates the transition temperature [2].

It is necessary to be able to deposit high quality $\mathrm{VO}_{2}$ films on conducting substrates in order to explore carrier conduction out-of-plane of the film. To date, $\mathrm{VO}_{2}$ films have primarily been grown on conducting substrates such as heavily-doped $\mathrm{Si}$ or Ge, and Pt [3-5]. As far as conducting oxide substrates are concerned; there is a recent report discussing the role of twin boundaries of $\mathrm{VO}_{2}$ grown on Ga-doped $\mathrm{ZnO}$ buffered $c$-sapphire [6]. $\mathrm{VO}_{2}$ films grown on conducting oxides would be of particular interest to explore all-oxide electronics wherein the underlayer could be used as an electrode for electron transport. Therefore, here we have studied the physical properties of $\mathrm{VO}_{2}$ grown on conducting oxide substrates namely $\mathrm{Nb}$-doped $\mathrm{SrTiO}_{3}$ single crystal substrate and $\mathrm{RuO}_{2}$ buffered $\mathrm{TiO}_{2}$ single crystal substrate.

\section{EXPERIMENTAL}


$\mathrm{VO}_{2}$ thin films $(\sim 200 \mathrm{~nm})$ were deposited by rf-sputtering on two representative conducting oxide substrates: $\mathrm{Nb}$-doped $\mathrm{SrTiO}_{3}(001)(\mathrm{Nb}: \mathrm{STO})$ or $\mathrm{RuO}_{2}$ (101) buffered $\mathrm{TiO}_{2}$ (101) single crystal substrates. The single crystals of $\mathrm{Nb}: \mathrm{STO}(\mathrm{Nb}$ weight concentration $1.0 \%)$ with resistivity of $0.0035 \mathrm{ohm} \cdot \mathrm{cm}$ were used as-obtained (from MTI Crystal) except for high pressure nitrogen cleaning before loading into a sputtering chamber. Crystalline $\mathrm{RuO}_{2}$ thin films were grown by pulsed chemical vapor deposition in a home-built tube reactor [7], with bis( $N, N^{\prime}$-di-tertbutylacetamidinato) ruthenium (II) dicarbonyl as the ruthenium precursor and oxygen as co-reactant gas. The ruthenium precursor was placed in a glass bubbler in an oven set at $140^{\circ} \mathrm{C}$, and it was delivered into the reactor tube with nitrogen as carrier gas in each precursor pulse. The precursor has a vapor pressure of $100 \mathrm{mTorr}$ at $140^{\circ} \mathrm{C}$, and the glass bubbler has a volume of $0.14 \mathrm{~L}$, therefore, an amount of $14 \mathrm{mTorr} \mathrm{L}$ precursor vapor was delivered during each pulse. While the ruthenium precursor was delivered, a gas mixture of oxygen and nitrogen $\left(\mathrm{O}_{2}: \mathrm{N}_{2}=1: 2\right.$ in partial pressure) was kept flowing at a total pressure of $450 \mathrm{mTorr}$. The deposition temperature was $280^{\circ} \mathrm{C}$. Given the pumping speed of $2.5 \mathrm{~L} / \mathrm{s}$, the exposure of the ruthenium precursor was estimated to be approximately $7.5 \mathrm{mTorr} s$ for each pulse. Several hundred pulses of ruthenium precursor were supplied to grow the $\mathrm{RuO}_{2}$ film. Rutile $\mathrm{TiO}_{2}(101)$ substrates supplied by MTI Corporation were used for growing epitaxial $\mathrm{RuO}_{2}$ films. Each substrate was treated with UV/ozone for 5 minutes to remove surface organic contaminants before deposition. The $\mathrm{RuO}_{2}$ film thickness is $\sim 38 \mathrm{~nm}$ with resistivity of $0.00008 \mathrm{ohm} \cdot \mathrm{cm}$. The sputtering was performed in an Ar environment at set pressure of 10 mTorr from a $\mathrm{V}_{2} \mathrm{O}_{5}$ target for 6 hours, with the substrate temperature and RF source power set at $550{ }^{\circ} \mathrm{C}$ and $120 \mathrm{~W}$, respectively. Detailed description of $\mathrm{VO}_{2}$ film growth by sputtering and deposition condition effects on properties can be found in previous reports $[4,8]$.

X-ray diffraction (XRD) experiments were first characterized by the Bruker D8 which has a conventional $1.6 \mathrm{~kW}$ sealed X-ray tube source, a horizontal circle Eulerian cradle and a 
Vantec2000 2D detector. The data were collected with $0.3 \mathrm{~mm}$ monocapillary lenses and a graphite monochromator at the incident-beam side. The $\mathrm{VO}_{2}$ film on $\mathrm{RuO}_{2}$ was further characterized by a triple-axis diffractometer, the Bruker D8 high resolution XRD (HRXRD) diffractometer, with $\mathrm{Cu} K \alpha$ radiation, configured with a $\mathrm{G}$ bel mirror and a $\mathrm{Ge}(022) \times 4$ asymmetric monochromator at the incident-beam side, and the Pathfinder, a scintillation point detector, at the receiving-side. Crystallographic characterization was accomplished with $2 \theta-\omega$ coupled scans, and a $\phi$ scan (for epitaxial film only). A Zeiss Ultra55 Field Emission Scanning Electron Microscope (FESEM) was employed to obtain microstructures and operated at $5 \mathrm{keV}$ with In-lens detector. X-ray photoelectron spectroscopy (XPS) measurements were performed in an ESCA SSX-100 spectrometer with $\mathrm{Al} K \alpha(1.4866 \mathrm{keV})$ as X-ray source. XPS depth profiling was assisted with Ar ion milling with spectra taken after every 10 minute etching. All the XPS data were analyzed with Casa-XPS software package. Au (200 nm) / Ti $(20 \mathrm{~nm})$ metal contacts with different sizes ranging from $50 \times 50 \mu \mathrm{m}^{2}$ to $500 \times 500 \mu \mathrm{m}^{2}$ were deposited in a Denton EBeam Evaporator with shadow mask. The electrical properties were measured in a probe station equipped with a hot stage and a Keithley 236 source meter.

\section{RESULTS AND DISCUSSION}

Figure 1 shows the $2 \theta$ - $\omega$ coupled X-ray diffraction patterns for $\mathrm{VO}_{2}$ film grown on $\mathrm{Nb}: \mathrm{STO}$ single crystals substrate and $\mathrm{RuO}_{2}$ buffered $\mathrm{TiO}_{2}$ single crystal substrates. The $\mathrm{VO}_{2}$ film on $\mathrm{Nb}$ :STO is highly textured, as seen in Figure 1a, the major peaks at $27.83^{\circ}, 57.44^{\circ} 2 \theta$ are attributed to the reflection of (011) and (022) plane of the monoclinic phase, and the other minor peaks belong to $\mathrm{VO}_{2}$ or the substrate. The high-resolution $\mathrm{XRD}$ characterization of $\mathrm{VO}_{2}$ film on 
$\mathrm{RuO}_{2}$ is shown in Figure $1 \mathrm{~b}$. The peaks at $35.77^{\circ}, 36.11^{\circ}, 37.13^{\circ}$, are ascribed to (101) plane of tetragonal $\mathrm{RuO}_{2}, \mathrm{TiO}_{2}$ and $\mathrm{VO}_{2}$ respectively. The as-deposited $\mathrm{RuO}_{2}(101)$ diffraction in the epitaxial film shifts from $35.05^{\circ}$ (for bulk single crystal) to $35.54^{\circ}$ approaching the substrate $\mathrm{TiO}_{2}$ (101) diffraction (at $36.08^{\circ}$ for single crystal). This indicates that the $\mathrm{RuO}_{2} d_{101}$ spacing is decreasing dominated by the decrease of the $c$ axis of $\mathrm{RuO}_{2}$ to match the substrate lattice (crystallographic information is shown in Table 1 [9-12]). After the $\mathrm{VO}_{2}$ growth, the $\mathrm{RuO}_{2}$ (101) peak further shifted towards higher angles at $35.77^{\circ}$. The in-plane orientation was determined from $\phi$ scan on (002) plane for both $\mathrm{TiO}_{2}$ substrate and $\mathrm{VO}_{2}$ film, suggesting epitaxial growth of $\mathrm{VO}_{2}$ on the $\mathrm{RuO}_{2}$ buffered $\mathrm{TiO}_{2}$ substrate, as shown in Figure $2 \mathrm{~b}$ inset.

Field emission SEM images show the morphology of the films grown on different substrates (Figure 2a-b). In Figure 2a, the "flower" like microstructure of $\mathrm{VO}_{2}$ film on $\mathrm{Nb}: \mathrm{STO}$ are composed of closely packed thin sheets, which could cause the highly oriented XRD patterns showed earlier. $\mathrm{VO}_{2}$ film on $\mathrm{RuO}_{2}$ buffered $\mathrm{TiO}_{2}$ shows inclined column structure with a larger grain size of about $200 \mathrm{~nm}$. Both films exhibit well defined crystalline grains, and the uniformity was checked by taking images across several regions. The thickness of both $\mathrm{VO}_{2}$ film on $\mathrm{Nb}: \mathrm{STO}$ or $\mathrm{RuO}_{2}$ buffered $\mathrm{TiO}_{2}$ are $\sim 200 \mathrm{~nm}$ as shown in SEM micrographs from film crosssection, Figure 2c-d. From Figure 2d, we can observe that the $\mathrm{RuO}_{2}$ buffer layer is $\sim 35 \mathrm{~nm}$.

The electrical properties of $\mathrm{VO}_{2}$ films grown on $\mathrm{Nb}: \mathrm{STO}$ and $\mathrm{RuO}_{2}$ layer were characterized in both in-plane and out-of-plane geometry, as shown in Figure 3, the normalized resistance $\left(R_{\mathrm{n}}\right.$ $\left.=R(T) / R\left(25{ }^{\circ} \mathrm{C}\right)\right)$ versus temperature curves (inset shows linear I-V curves from which the resistance values were determined). For $\mathrm{VO}_{2}$ films on $\mathrm{Nb}$ :STO, the MIT temperature ( $\left.\mathrm{T}_{\mathrm{MIT}}\right)$, defined as the peak position in the derivative curve of corresponding resistance versus temperature curve, was determined to be $\sim 58.5{ }^{\circ} \mathrm{C}$ and $54.8^{\circ} \mathrm{C}$ for heating and cooling from the 
in-plane measurement, as shown in Figure $3 \mathrm{~b}$. The out-of-plane measurement shows similar $\mathrm{T}_{\mathrm{MIT}}$ with $\sim 58.1{ }^{\circ} \mathrm{C}$ and $54.4{ }^{\circ} \mathrm{C}$ for heating and cooling process respectively, detailed MIT characteristics are summarized in Table 2. In Figure 3a, in plane $R_{n} \sim T$ measurement of the $\mathrm{VO}_{2}$ film on $\mathrm{Nb}$ :STO shows a larger resistance ratio $\left(\Delta A=R\left(25^{\circ} \mathrm{C}\right) / R\left(100^{\circ} \mathrm{C}\right)\right)$ of 397 compared to the out of plane ratio of 79 . The lower transition order for out-of-plane measurement was also observed in a recent study, which discussed the twin boundary effect on MIT thermal hysteresis [6]. Yang et al described that the thermal hysteresis of the out of plane measurement of epitaxial growth $\mathrm{VO}_{2}$ on Ga:ZnO buffered $c$-sapphire with current flow parallel to the twin boundaries was considerably reduced compared to in plane measurement of epitaxial growth $\mathrm{VO}_{2}$ on $\mathrm{ZnO}$ buffered $c$-sapphire where current flows normal to the boundaries. However, the thermal hysteresis ( $\triangle \mathrm{H}$ : difference between the critical temperature of heating and cooling curves) of the $\mathrm{VO}_{2}$ film on $\mathrm{Nb}: \mathrm{STO}$ for both in plane and out of plane measurement is similar, i.e. $\sim 3.7^{\circ} \mathrm{C}$, which could be explained by the textured nature of our film.

Figure 3c shows the $R_{n} \sim T$ curves of $\mathrm{VO}_{2}$ film on $\mathrm{RuO}_{2}$ buffered $\mathrm{TiO}_{2}$ measured in both inplane and out-of-plane geometry (inset shows representative linear I-V plots). This film shows a small resistance change in both in-plane and out-of-plane measurement compared to $\mathrm{VO}_{2}$ films grown on $\mathrm{Nb}$ :STO deposited at the same time. The current flow in the low resistivity $\mathrm{RuO}_{2}$ layer could explain the small resistance change for the in-plane measurement of a high quality $\mathrm{VO}_{2}$ film, while this does not necessarily explain the small resistance change observed in the out of plane measurement. Since the phase transition is quite sensitive to stoichiometry, this smaller transition might indicate that this film is off-stoichiometric. It is interesting to note that this film shows a two step transition, as shown in Figure $3 \mathrm{~d}$ (derivative curve of the in-plane measurement, with two transitions at 48.7 and $61.0{ }^{\circ} \mathrm{C}$ during heating, and 45.6 and $57.9{ }^{\circ} \mathrm{C}$ 
during cooling, respectively). The transition width ( $\Delta \mathrm{T}$ : full width at half maximum of derivative curve) for these four peaks ranges from 8.7 to $9.2{ }^{\circ} \mathrm{C}$, and the width of thermal hysteresis for both transition is $3.1{ }^{\circ} \mathrm{C}$. The out-of-plane measurement shows the same two step transition with the $\mathrm{T}_{\mathrm{MIT}}$ at 48.5 and $59.8{ }^{\circ} \mathrm{C}$ during heating, and 46.0 and $57.3{ }^{\circ} \mathrm{C}$ during cooling, respectively. The thermal hysteresis widths for both transitions in the out-of-plane measurement are $2.5^{\circ} \mathrm{C}$ which is narrower than the in plane measurement. This is consistent with the recent study that out of plane measurement shows narrower width of thermal hysteresis due to less grain boundaries in a columnar growth epitaxial film containing twin boundaries [6].

$\mathrm{X}$-ray photoelectron spectroscopy (XPS) depth profiling was carried out on both sets of $\mathrm{VO}_{2}$ films grown on $\mathrm{Nb}: \mathrm{STO}$ and $\mathrm{RuO}_{2}$ buffered $\mathrm{TiO}_{2}$, as shown in Figure 4. In the surface full scan spectra, except for features arising from $\mathrm{V}$ and $\mathrm{O}$, there are also $\mathrm{N} 1 s$ and $\mathrm{C} 1 s$ which arises from surface contamination and $\mathrm{Au}$ from electrode fabrication. The adventitious $\mathrm{C} 1 \mathrm{~s}$ peak was assumed to have a binding energy of $284.8 \mathrm{eV}$ [13], and used to calibrate the binding energy of vanadium. High resolution XPS spectra were focused around the $\mathrm{O} 1 s$ and V $2 p$ region.

Figure $4 \mathrm{a}$ and $\mathrm{c}$ shows the depth dependent XPS full scan spectra of $\mathrm{VO}_{2}$ film on different substrates with the depth indicated by etching time, the curves are vertically shifted for clarity. The etching rate for $\mathrm{VO}_{2}$ was calibrated to be $\sim 0.5 \mathrm{~nm} / \mathrm{min}$. The distance $(d)$ to the surface is estimated according to the etch rate and time. Figure $4 \mathrm{~b}$ summarizes the elements $\mathrm{V}, \mathrm{O}$ and $\mathrm{Sr}$ concentration profile, which is calculated according to the relative sensitivity factor (RSF)-scaled areas under $\mathrm{V} 2 p_{3 / 2}, \mathrm{O} 2 s$ and $\mathrm{Sr} 3 p_{3 / 2}$ peaks after Shirley background subtraction. Due to any preferential sputtering rate of different elements, the absolute values of the atomic percentage may not be accurate, and hence we just compare the relative peak to peak intensity here. Both oxygen and vanadium are evenly distributed in the bulk part of the film (15-200 nm from 
surface). The fraction of V decreased from about $30 \%$ after 410 mins etching to $15 \%$ after 450 mins etching and the relative fraction of $\mathrm{Sr}$ correspondingly increase to $17 \%$ after 450 mins etching. The slow decreasing rate (the profile tail) is commonly observed in the XPS depth profiling $[14,15]$, since surface roughness as well as etching spot edge effect may blur the profile.

For $\mathrm{VO}_{2}$ film on $\mathrm{RuO}_{2}$ buffered $\mathrm{TiO}_{2}$, as shown in Figure 4c, the Ru peaks appeared after 350 min etching at $\sim 175 \mathrm{~nm}$ to the surface. Then the intensity of Ru peak continuously increased to $18 \%$ until 440 min etching with the presence of Ti peak in the spectra. Figure $4 \mathrm{~d}$ summarized the relative fraction of the elements calculated according to the RSF-scaled areas under V 2p $p_{3 / 2}$, $\mathrm{O} 2 s, \mathrm{Ru} 3 p_{1 / 2}$ and Ti $2 s$ peaks. The $\mathrm{V}$ fraction decreased from $31 \%$ to $17 \%$ in 90 mins etching from the observation of Ru peaks (after 350 mins etching) to the presence of Ti peaks (after 440 mins etching) from $\mathrm{TiO}_{2}$ substrate. The etching rate of $\mathrm{RuO}_{2}$ film on $\mathrm{TiO}_{2}$ was calibrated to be $\sim 1 \mathrm{~nm} / \mathrm{min}$ based on both as deposited film and the film annealed under the $\mathrm{VO}_{2}$ film deposition condition. From SEM image in Figure 2d, we measured the thickness of $\mathrm{RuO}_{2}$ layer is approximately $35 \mathrm{~nm}$, which should be etched through in $\sim 40 \mathrm{~min}$. We, however, see that it takes $90 \mathrm{~min}$ from the observation of Ru to the observation of Ti peak. This difference and the slower decreasing rate of $\mathrm{V}$ concentration compared to the film on $\mathrm{Nb}$ :STO suggest that a solid solution, $\mathrm{V}_{1-\mathrm{x}} \mathrm{Ru}_{\mathrm{x}} \mathrm{O}_{2}$, is likely formed at the interface. In addition, the $\mathrm{VO}_{2}$ film is $\sim 206 \mathrm{~nm}$ thick as shown in the SEM cross-section image, while we start to observe Ru peak at $\sim 175 \mathrm{~nm}$. Ru might diffuse into the $\mathrm{VO}_{2}$ layer to the extent of $\sim 30 \mathrm{~nm}$ (which is expected to take about $50 \mathrm{~min}$ etch time), and is consistent with the 90 min etching time from observation of Ru to Ti peaks in the XPS measurement. According to previous studies, a rutile structure will be sustained when $0.025<\mathrm{x}<0.75[2,16]$. The formation of a solid solution of $\mathrm{V}_{1-\mathrm{x}} \mathrm{Ru}_{\mathrm{x}} \mathrm{O}_{2}$ could cause the shift of 
$\mathrm{RuO}_{2}$ (101) diffraction towards the higher angle as we observed [17]. It is known that transition temperature of $\mathrm{VO}_{2}$ can be reduced by $\mathrm{Ru}$ doping $[2,16]$, so the $\mathrm{V}_{1-\mathrm{x}} \mathrm{Ru}_{\mathrm{x}} \mathrm{O}_{2}$ is expected to show a different transition temperature to the $\mathrm{VO}_{2}$ film on top layer. Therefore we speculate that the overlap of these two transitions resulting in the two step transition in $R_{n} \sim T$ curves of the $\mathrm{VO}_{2}$ film grown on $\mathrm{RuO}_{2}$ buffered $\mathrm{TiO}_{2}$.

Next, we consider the relative fraction of the vanadium dioxide $\left(\mathrm{V}^{4+}\right)$ phase. In the high resolution XPS spectra, we focused on the $\mathrm{V} 2 p_{3 / 2}$ peaks to compare the compositional difference between various films. After Shirley background subtraction, the V $2 p_{3 / 2}$ peaks were deconvoluted into two peaks. At the surface, the peaks at 516.9(2) and 515.8(2) $\mathrm{eV}$ are assigned to $\mathrm{V}^{5+}$ and $\mathrm{V}^{4+}$ respectively), as shown in Figure 5a [18]. In the interior region of the film, the peaks are located at 515.8(2) eV and 513.7(2) eV and attributed to $\mathrm{V}^{4+}$ and $\mathrm{V}^{2+}$, respectively, as shown in Figure $5 b[4,19]$. The average fraction of $\mathrm{V}^{4+}$ for interior region of $\mathrm{VO}_{2}$ films are $\sim 71 \%$ on $\mathrm{Nb}: \mathrm{STO}$ and $\sim 68 \%$ on $\mathrm{RuO}_{2}$ buffered $\mathrm{TiO}_{2}$, while the surface of the films are composed of about $55 \%$ of $\mathrm{V}^{4+}$ on both films, as shown in Figure 5c. It also shows that the $\mathrm{V}^{4+}$ fraction decreased with decreasing vanadium content at the interface of $\mathrm{VO}_{2}$ film on $\mathrm{Nb}$ :STO, while the $\mathrm{V}(\mathrm{IV})$ concentration was relatively unchanged for $\mathrm{VO}_{2}$ film on $\mathrm{RuO}_{2}$ buffered $\mathrm{TiO}_{2}$ indicating that the V(IV) state is stabilized in the solid solution.

Next, we have investigated the electrically-driven metal-insulator transition (referred to as EMIT) with a $\mathrm{VO}_{2}$ film grown on $\mathrm{Nb}$-doped $\mathrm{SrTiO}_{3}$ substrate. Experiments were carried out in both in-plane and out-of-plane geometry to understand the role of the substrate in influencing the overall current-voltage characteristics. Figure 6 (a) and (b) show I-V plots measured in the outof-plane mode (Figure 6(b) shows the zoom-in view of fewer I-V curves in log scale for clarity) at different temperatures. The out-of-plane curves show a small hysteresis loop when sweeping 
current up and down that on its own is not clear if we can ascribe it to the phase transition. However one can get additional insights from the in-plane measurements on the same sample. In-plane results (Figure 6(c)) show large current jumps and the threshold voltage dependence on temperature in agreement with previous studies on $\mathrm{VO}_{2}[20,21]$. This demonstrates that $\mathrm{VO}_{2}$ film on Nb:STO does show the electrically-driven transition. The in-plane E-MIT happens at $\sim 12$ $\mathrm{V}$ which is larger than the out-of-plane value because the spacing of electrodes in this geometry is a few tens of micrometers that is larger than the $\sim 200 \mathrm{~nm}$ separation for the out-of-plane measurement. In the out-of-plane geometry, the $\mathrm{Nb}$ :STO substrate acts as a resistor in series with $\mathrm{VO}_{2}$. The resistance of $\mathrm{Nb}: \mathrm{SrTiO}_{3}$ becomes larger as the voltage increases (which can be seen for example from $\mathrm{I}-\mathrm{V}$ data at $100{ }^{\circ} \mathrm{C}$ where the resistance mainly comes from $\mathrm{Nb}$ :STO). When $\mathrm{VO}_{2}$ reaches threshold voltage for switching, there would have been a sharp current jump. However, since the I-V curve of $\mathrm{Nb}$ :STO is not linear, such a large current will need a much larger external voltage than the applied bias. As a consequence, the current only changes gradually. The larger the resistance of $\mathrm{Nb}: \mathrm{STO}$, the smaller the hysteresis loop. This is likely why the out-plane I-V at $55^{\circ} \mathrm{C}$ has a larger hysteresis than that at $25^{\circ} \mathrm{C}$ (due to decrease in resistance of $\mathrm{Nb}: \mathrm{STO}$ ). Although the resistance of $\mathrm{Nb}$ :STO continues to decrease above $60{ }^{\circ} \mathrm{C}$, the $\mathrm{I}-\mathrm{V}$ hysteresis becomes smaller because the E-MIT magnitude decreases as temperature increases. Similarly, the out-of-plane measurement shows a smaller metal-insulator transition magnitude than in-plane due to additional series resistance from $\mathrm{Nb}$ :STO substrate. The shape of the out-of-plane I-V curve may be explained as the following: at small voltages $(\sim 0-1.5 \mathrm{~V})$ the shape is primarily determined due to the $\mathrm{VO}_{2}$ layer contribution, which looks similar to the in-plane I-V curve below threshold voltage. At intermediate voltages $(\sim 1.5-2 \mathrm{~V})$, the current increases gradually because of the series resistance of $\mathrm{Nb}$ :STO. At larger voltages ( 2-3 V), the I-V curve 
corresponds to $\mathrm{Nb}: \mathrm{STO}$, and resembles $\mathrm{I}-\mathrm{V}$ measurements at $\sim 100^{\circ} \mathrm{C}$ when the $\mathrm{VO}_{2}$ layer is in the conducting state.

\section{SUMMARY}

Textured vanadium oxide films have been grown on conducting oxide substrates by rf sputtering, and their physical properties have been studied. The $\mathrm{VO}_{2}$ film on $\mathrm{Nb}$-doped $\mathrm{SrTiO}_{3}$ shows over two orders of magnitude resistance change across the transition. The $\mathrm{VO}_{2}$ film on $\mathrm{RuO}_{2}$ buffered $\mathrm{TiO}_{2}$ shows a two step transition. From photoelectron spectroscopy, it is likely an interfacial $\mathrm{V}_{1-\mathrm{x}} \mathrm{Ru}_{\mathrm{x}} \mathrm{O}_{2}$ layer is formed with a lower transition temperature resulting in the two step transition.

\section{ACKNOWLEDGMENT}

We are grateful to National Science Foundation Grant DMR-0952794 and Office of Naval Research Grant N00014-10-1-0131 for financial support. This work was performed in part at the Center for Nanoscale Systems (CNS), a member of the National Nanotechnology Infrastructure Network (NNIN), which is supported by the National Science Foundation under NSF award no. ECS-0335765. 


\section{REFERENCES}

[1] L.A. Ladd, W. Paul, Solid State Commun., 7 (1969) 425.

[2] J.B. Goodenough, J. Solid State Chem., 3 (1971) 490.

[3] D. Ruzmetov, G. Gopalakrishnan, J.D. Deng, V. Narayanamurti, S. Ramanathan, J. Appl. Phys., 106 (2009) 083702.

[4] Z. Yang, C. Ko, S. Ramanathan, J. Appl. Phys., 108 (2010).

[5] M.J. Lee, Y. Park, D.S. Suh, E.H. Lee, S. Seo, D.C. Kim, R. Jung, B.S. Kang, S.E. Ahn, C.B. Lee, D.H. Seo, Y.K. Cha, I.K. Yoo, J.S. Kim, B.H. Park, Adv. Mater., 19 (2007) 3919.

[6] T.H. Yang, C.M. Jin, H.H. Zhou, R.J. Narayan, J. Narayan, Appl. Phys. Lett., 97 (2010) 702101.

[7] J.S. Becker, E. Kim, R.G. Gordon, Chem. Mater., 16 (2004) 3497.

[8] D. Ruzmetov, K.T. Zawilski, V. Narayanamurti, S. Ramanathana, J. Appl. Phys., 102 (2007) 113715.

[9] F. Swanson, Natl. Bur. Stand. (U.S.) Circ., 3 (1953) 539.

[10] I.E. Grey, C. Li, C.M. MacRae, L.A. Bursill, J Solid State Chem., 127 (1996) 240.

[11] C.E. Boman, Acta Chem. Scand., 24 (1970) 116.

[12] K.D. Rogers, Powder Diffraction, 8 (1993) 240.

[13] G. Sch n, J. Electron Spectrosc., 1 (1972) 377.

[14] S. Oswald, W. Brückner, Surf. Interface Anal., 36 (2004) 17.

[15] P.C. Liao, S.Y. Mar, W.S. Ho, Y.S. Huang, K.K. Tiong, Thin Solid Films, 287 (1996) 74.

[16] B.L. Chamberland, D.B. Rogers, patent, in U.S.(1970) patent No. 3,542,697.

[17] K. Yokoshima, T. Shibutani, M. Hirota, W. Sugimoto, Y. Murakami, Y. Takasu, J. Power Sources, 160 (2006) 1480.

[18] G.A. Sawatzky, D. Post, Phys. Rev. B, 20 (1979) 1546.

[19] D.H. Youn, H.T. Kim, B.G. Chae, Y.J. Hwang, J.W. Lee, S.L. Maeng, K.Y. Kang, J. Vac. Sci. Technol. A, 22 (2004) 719.

[20] H.T. Kim, B.G. Chae, D.H. Youn, G. Kim, K.Y. Kang, S.J. Lee, K. Kim, Y.S. Lim, Appl. Phys. Lett. , 86 (2005) 242101.

[21] C. Ko, S. Ramanathan, Appl. Phys. Lett., 93 (2008) 252101. 
Fig. $12 \theta-\omega$ scan X-ray diffraction patterns of $\mathrm{VO}_{2}$ films grown on different substrates: (a) $\mathrm{VO}_{2}$ on $\mathrm{Nb}$-doped $\mathrm{SrTiO}_{3}(001)$ (VNST) and (b) $\mathrm{VO}_{2}$ on $\mathrm{RuO}_{2}$ buffered $\mathrm{TiO}_{2}$ (101) (VRT). Inset in figure 1(b) is the $\phi$ scan of (002) plane of film $\mathrm{VO}_{2}$ and substrate $\mathrm{TiO}_{2}$
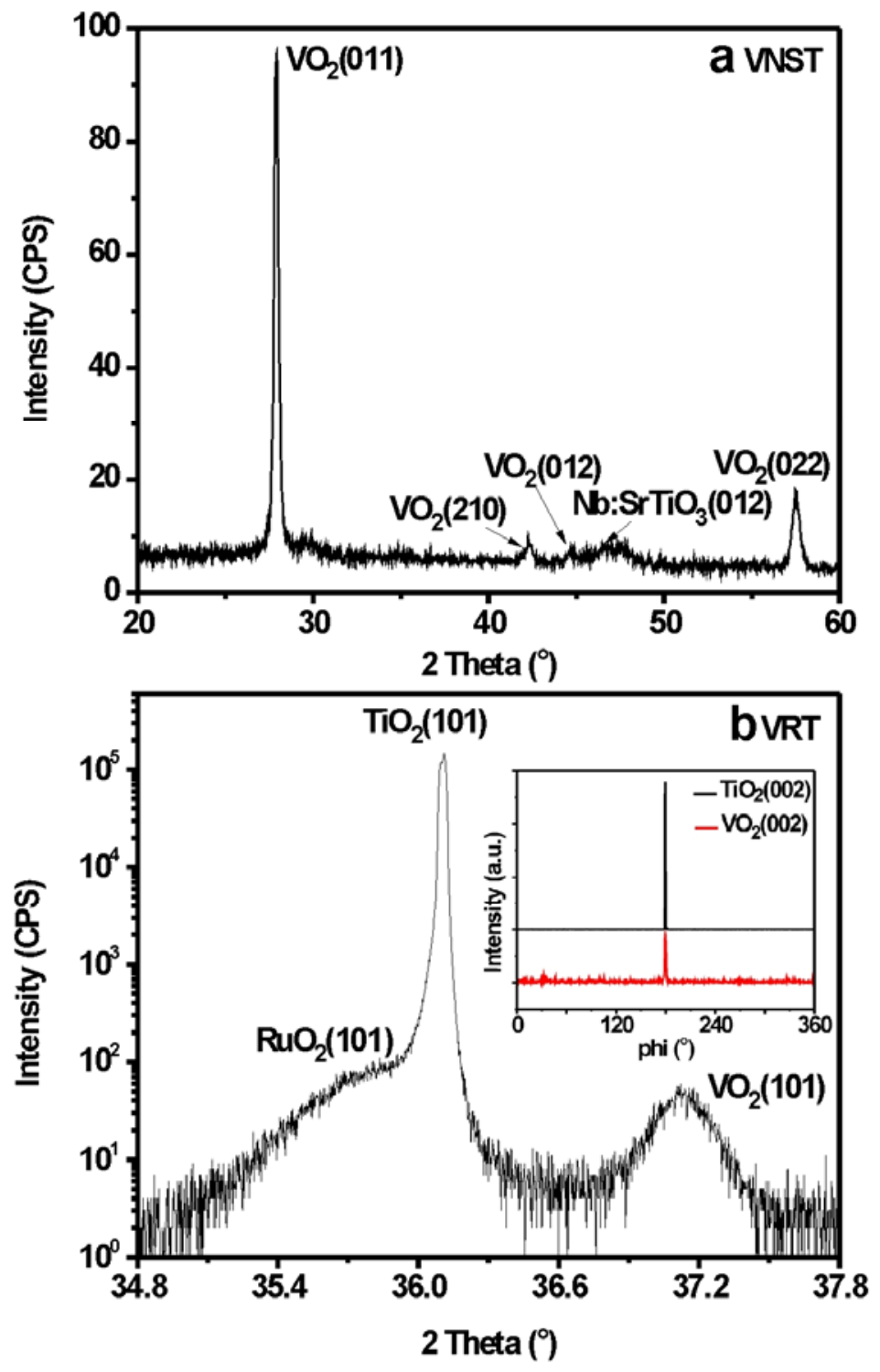
Fig. 2 Plan view and cross-section FESEM images of as-deposited $\mathrm{VO}_{2}$ films grown on different substrates: (a, c) Nb-doped $\mathrm{SrTiO}_{3}$, (b, d) $\mathrm{RuO}_{2}$ buffered $\mathrm{TiO}_{2}$ respectively

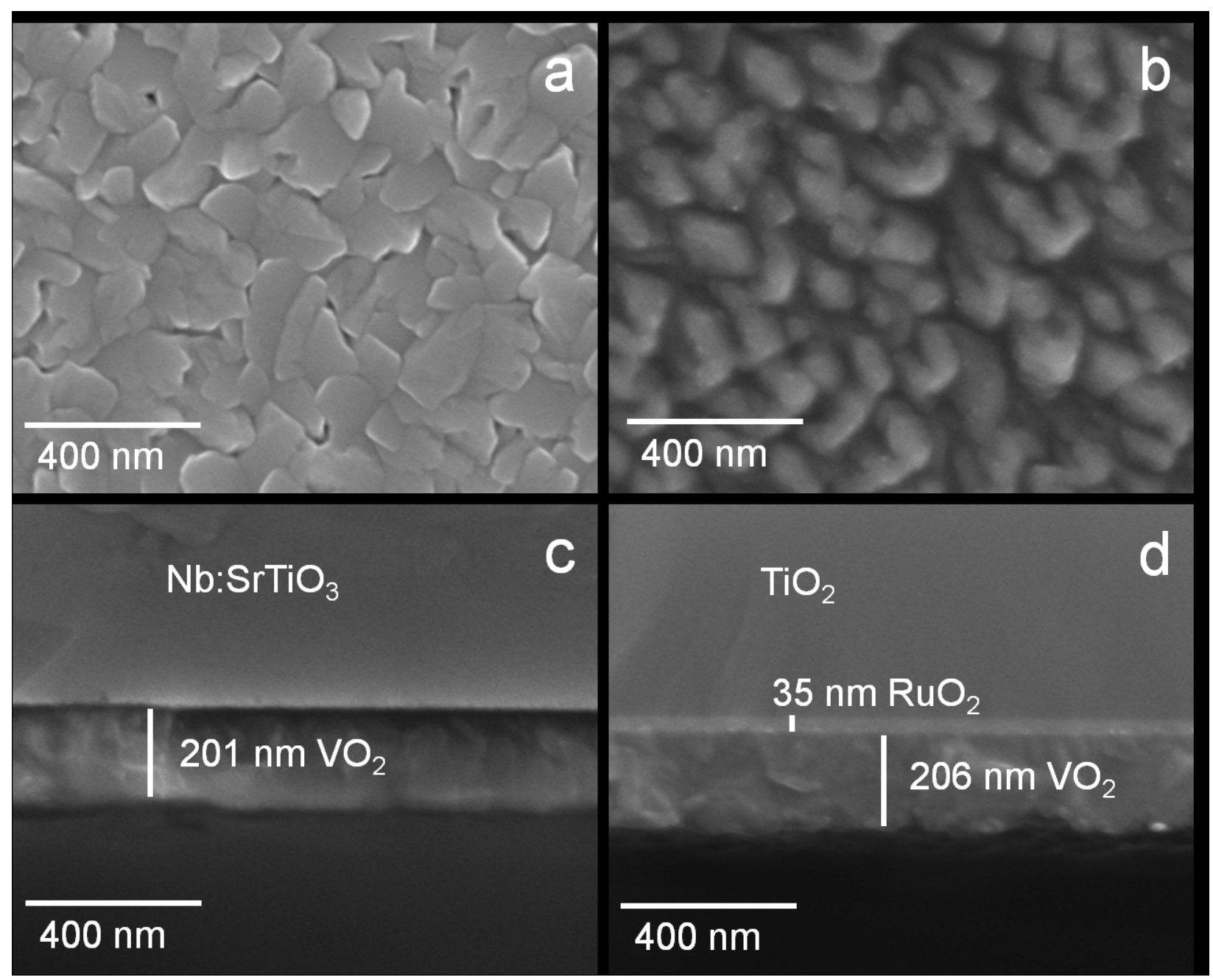


Fig. 3 (a) Normalized resistance plotted as a function of temperature for $\mathrm{VO}_{2}$ films grown on $\mathrm{Nb}$ doped $\mathrm{SrTiO}_{3}$, (b) derivative plot for in-plane measurement from which we extract the phase transition characteristics (c) normalized resistance plot for $\mathrm{VO}_{2}$ grown on $\mathrm{RuO}_{2}$ buffered $\mathrm{TiO}_{2}$, insets show the derivative curves for the in-plane measurement and (d) corresponding derivative plot of in-plane resistance versus temperature Table 2 summarizes the phase transition characteristics.
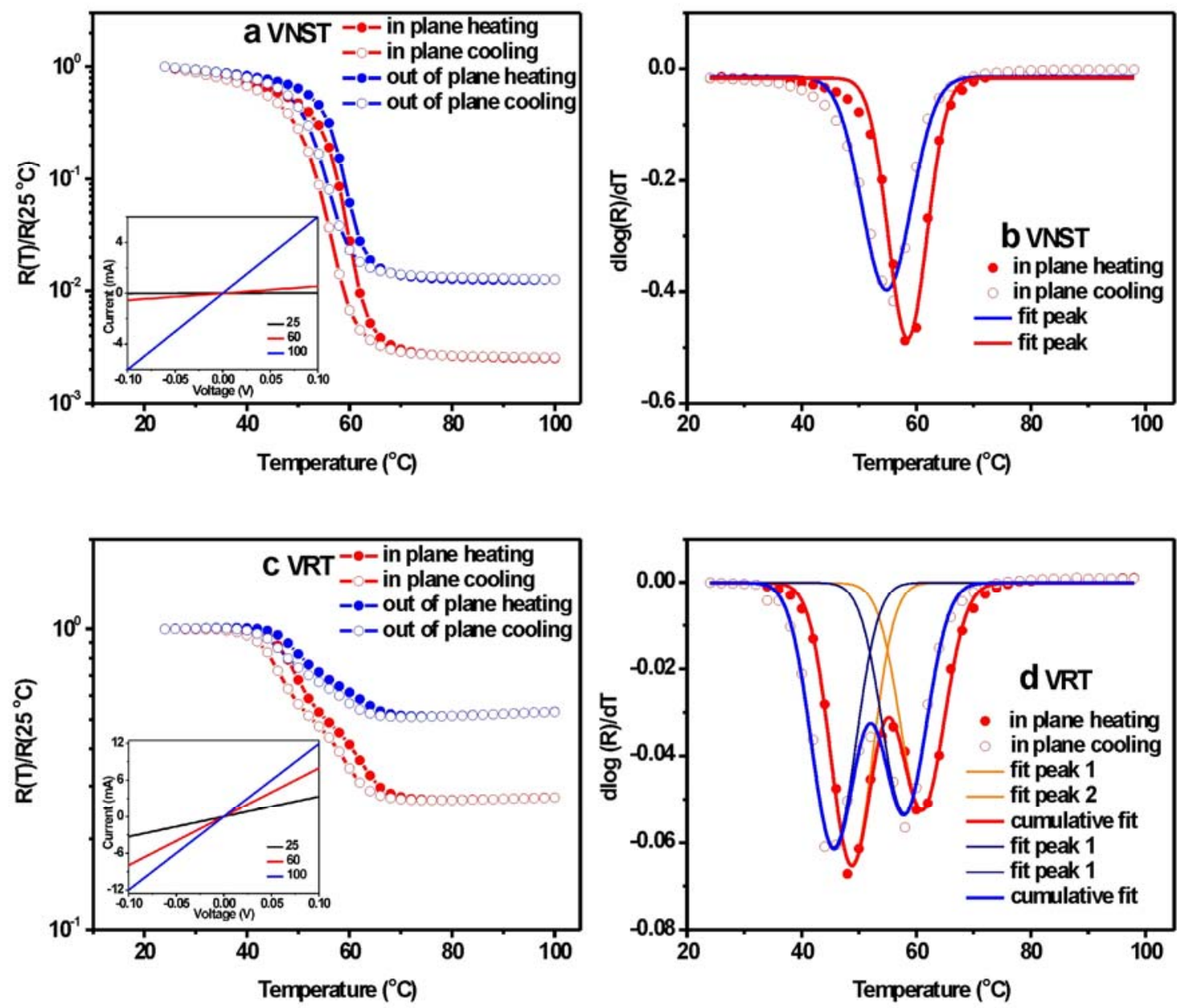
Fig. 4 XPS spectra of $\mathrm{VO}_{2}$ films grown on: (a) Nb-doped $\mathrm{SrTiO}_{3}$, (c) $\mathrm{RuO}_{2}$ buffered $\mathrm{TiO}_{2}$ and compositional depth profile of $\mathrm{VO}_{2}$ film on: (b) Nb-doped $\mathrm{SrTiO}_{3}$, (d) $\mathrm{RuO}_{2}$ buffered $\mathrm{TiO}_{2}$.
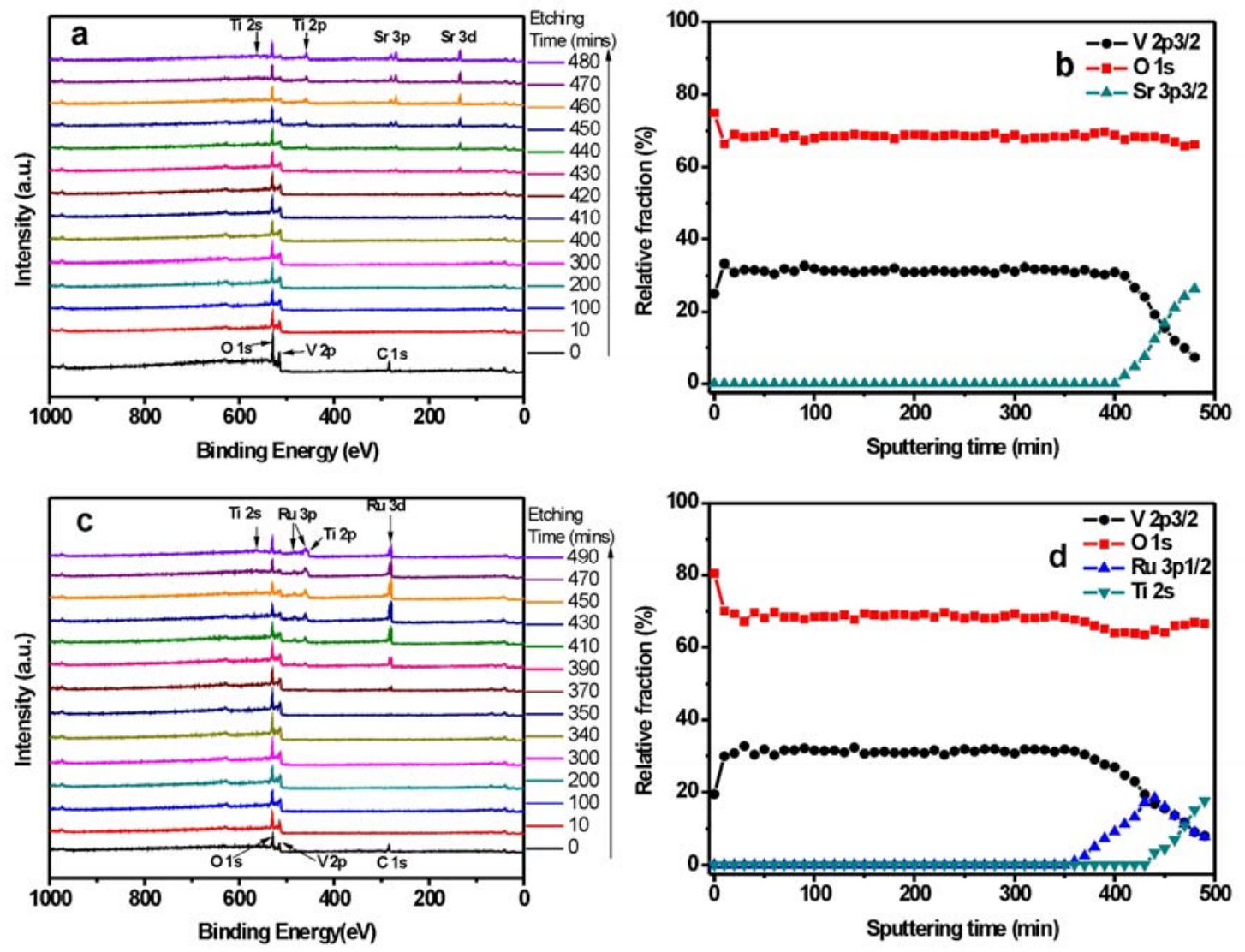
Fig. 5 De-convolution of high resolution XPS V2 $p_{3 / 2}$ peak (a) on surface and (b) in bulk region in $\mathrm{VO}_{2}$ film, (c) V2 $p_{3 / 2}$ relative fraction. VNST: $\mathrm{VO}_{2}$ on $\mathrm{Nb}$ doped $\mathrm{SrTiO}_{3}$ and VRT: $\mathrm{VO}_{2}$ on $\mathrm{RuO}_{2}$ buffered $\mathrm{TiO}_{2}$
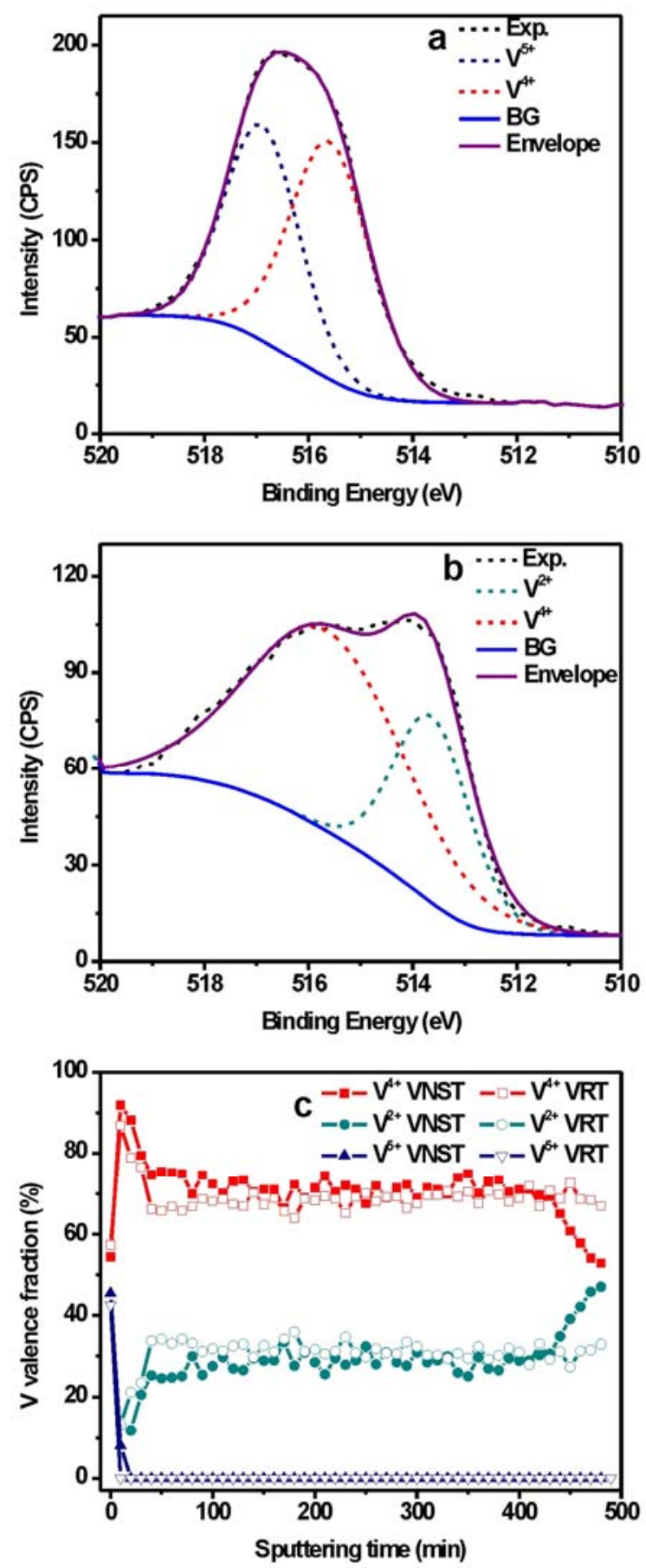
Fig. 6 Voltage-driven metal-insulator transition: (a) Out-of-plane current-voltage measurement on $\mathrm{VO} 2$ film grown on $\mathrm{Nb}$-doped $\mathrm{SrTiO}_{3}$ and (b) close-up view of representative $\mathrm{I}-\mathrm{V}$ curves at various temperatures, (c) in-plane measurement of the current-voltage curves at various temperatures.
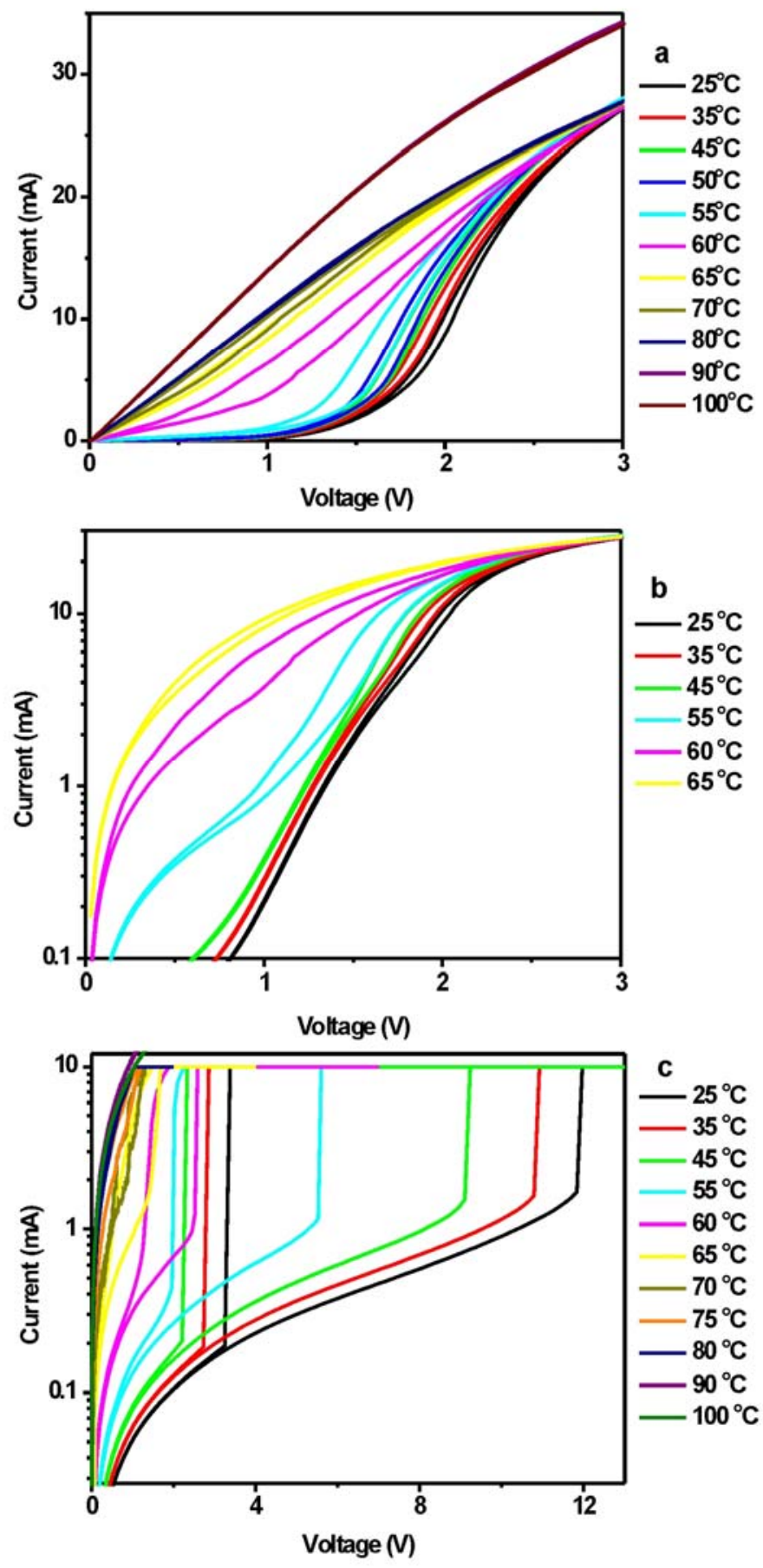
Table 1. Lattice parameters of various materials considered in this study.

\begin{tabular}{cccc}
\hline \hline \multirow{2}{*}{ Substrates } & Space group & \multicolumn{2}{c}{ Lattice parameter $(\AA)$} \\
\cline { 3 - 4 } & & 3.905 & $c$ \\
\hline $\mathrm{SrTiO}_{3}$ & $P m-3 m$ & 4.594 & - \\
$\mathrm{TiO}_{2}$ & $P 4_{2} / m n m$ & 4.492 & 2.959 \\
$\mathrm{RuO}_{2}$ & $P 4_{2} / m n m$ & 4.554 & 3.106 \\
$\mathrm{VO}_{2}(\mathrm{HT})$ & $P 4_{2} / m n m$ & $a: 5.753, b: 4.526$ & 2.856 \\
$\mathrm{VO}_{2}(\mathrm{LT})$ & $P 2_{1} / c$ & \multicolumn{3}{c}{$a .383$} \\
\hline \hline
\end{tabular}

Table 2. Phase transition characteristics of $\mathrm{VO}_{2}$ films grown on different substrates.

\begin{tabular}{ccccc}
\hline \hline \multicolumn{1}{c}{ Substrates } & $\mathrm{T}_{\text {MIT }}\left({ }^{\circ} \mathrm{C}\right)$ & $\Delta \mathrm{H}\left({ }^{\circ} \mathrm{C}\right)$ & $\Delta \mathrm{A}$ & $\Delta \mathrm{T}\left({ }^{\circ} \mathrm{C}\right)$ \\
\hline $\mathrm{Nb}: \mathrm{SrTiO}_{3}(001)$ & $58.5(\mathrm{H}), 54.8(\mathrm{C})$ & 3.7 in plane & 397 & $8.0 / 10.1$ \\
$\mathrm{Nb}_{\mathrm{SrTiO}_{3}(001)}$ & $58.1(\mathrm{H}), 54.4(\mathrm{C})$ & 3.7 out plane & 79 & $7.4 / 9.3$ \\
$\mathrm{RuO}_{2}(101)$ & $48.7(\mathrm{H}), 45.6(\mathrm{C})$ & 3.1 in plane & 3.6 & $8.7 / 9.1$ \\
& $61.0(\mathrm{H}), 57.9(\mathrm{C})$ & & & $9.1 / 9.2$ \\
$\mathrm{RuO}_{2}(101)$ & $48.5(\mathrm{H}), 46.0(\mathrm{C})$ & 2.5 out plane & 1.9 & $8.6 / 9.2$ \\
& $59.8(\mathrm{H}), 57.3(\mathrm{C})$ & & & $12.0 / 10.3$ \\
\hline \hline
\end{tabular}

